\title{
ЛИРИКА СЕМЕНА ДАНИЛОВА: АКСИОЛОГИЯ КОНЦЕПТУАЛЬНЫХ ОБРАЗОВ
}

\author{
SEMYON DANILOV'UN LİRIĞİ: KAVRAMSAL ŞEKILLERİN \\ AKSIOLOJISI
}

LYRICS OF SEMYON DANILOV: AXIOLOGY OF CONCEPTUAL IMAGES

\author{
Прасковья Васильевна Сивцева-МАКСИМОВА \\ (Praskovya V. Sivtseva-MAKSIMOVA)*
}

\begin{abstract}
АННОТАЦИЯ
В статье анализируется поэтика С.П.Данилова (1917 - 1978) в формах раскрытия лирических концептов как индивидуальное своеобразие стиля. Доказывается, что лирические раздумья воплощаются в системе сложной спирали размышлений над образами фольклорного начала, а также в представлении реалистических деталей общественной жизни в контексте народного восприятия мира частью вечной природы. Концепты, основанные на образах якутского эпоса олонхо и лирических пейзажах, отличаются раскрытием их интегрирующей функции. Дается специальный анализ последнего сборника поэта, где наблюдаются формы перетекания предмета лирического размышления в семантически открытый образ-представление, сопоставляемый с проблемами современной жизни общества.

Ключевые слова: якутская поэзия, лирический образ, концепты, авторский универсум, книга стихов.
\end{abstract}

\section{ÖZ}

Makalede C. P. Danilov’un şiirleri (1917 - 1978) yazı uslubunun özel kavramsal şekli açısından tetkik edilmiştir. Ayrıca liriksel düşüncelerin ilkel folklör şekilleri olarak bu tarz şiirlerin bileşik sisteminde cisimlendirildiği ve daimi doğanın bir parçası olarak halk algısının toplumun gerçek simgesi olduğu açıklanmıştır. Olonkho ve lirik tarzlı Yakut destanların kavramları ifşa edici ve bütünleştiricidir. Makalede yazarın son şiirler kitabı özellikle tetkik edilmiş ve lirik tarda ifade edilen konular toplumun çağdaş sorunları ile karşılaştırılmıştır.

Anahtar Kelimeler: Yakutça şiirler, liriksel şekiller, algılar, yazarın evrenliği, şiir kitab1.

* Доктор филологических наук, профессор, Северо-Восточный федеральный университет им. М.К. Аммосова Россия, г. Якутск (Doctor of Philology, Professor North-Eastern Federal University named after M. K. Ammosov Russia, Yakutsk) 


\section{ABSTRACT}

In article is analyzed S. Danilov's poetics (1917 - 1978) in forms of disclosure of lyrical concepts as an individual originality of style. It is proved that lyrical thoughts are embodied in system of a difficult spiral of reflections over images of the folklore beginning, and also in representation of realistic details of public life in the context of national perception of the world part of the eternal nature. The concepts based on images of the Yakut epos olonho and lyrical landscapes, differ in disclosure of their integrating function. It is given the special analysis of the last collection of the poet where forms of an overflowing of a subject of lyrical reflection in semantic open image representation compared with problems of modern life of society are observed.

Key words: Yakut poetry, lyrical image, concepts, author's universum, book of verses.

Народный поэт Якутии Семен Петрович Данилов (20.03.1917- 27.11.1978) изучал фольклор, историю и литературу, с восхищением писал об уникальности олонхо. С 1961 года плодотворно руководил Союзом писателей Якутии. При его непосредственном участии были изданы произведения классиков и современных писателей на русском языке. Осуществлено начатое якутскими поэтами еще в 1940-е годы издание на русском языке олонхо «Ньургун Боотур Стремительный» в переводе известного эпосоведа Владимира Державина. Первые книги поэта: «Мин дойдум» («Моя родина», 1949), «Кыраһа суруга» («Следы на пороше», 1955) получили широкое признание читателей. Его самобытное художественное наследие приравнивается образцам высокой лирики.

Семен Данилов печатается с 1937 года. В его стихах, проникнутых особым самоуглубленным лиризмом, разносторонне раскрывается образ родной земли. С самого начала в его поэзии задушевность создает в произведениях естественную гармонию содержания с проникнутым мудростью чувством любви к природе, доверчивым восхищением человеком труда. Впоследствии поэт выражает эту одну большую любовь по-разному, раскрывает в стихотворениях индивидуальное авторское видение мира, опираясь на «ключевые слова культуры» именно с учетом их аксиологически ориентированных художественных возможностей и смыслов. В этом плане логично то, что основным мотивом в лирических размышлениях Семена Данилова являются «воспоминания». Именно реальность прошлого выступает в его лирике гарантом верности, ощутимости образа. С другой стороны, данная особенность обеспечивает в стихах поэта раскрытие избранной темы во временной протяженности. Отсюда раздумья поэта воплощаются не столько в создании яркого образа, сколько в поэтической системе сложной спирали размышлений над образом, углубленными реалистическими деталями общественной жизни или утонченным народным восприятием привычной действительности. Таким образом, концепты в лирике Семена Данилова отличаются раскрытием новой или обновленной обобщающей и интегрирующей функции национальных образов, представляющих в поэтическом контексте неповторимо индивидуальный авторский универсум.

В этом ракурсе мы опираемся на определение концепта «как смысловой структуры, воплощенной в устойчивых образах, повторяющихся в границах определенного литературного ряда, и обладающей культурно значимым содержанием, семиотичностью и ментальной природой» [Володина, с.19]. При этом принципиально учитываем «понятия первичный концепт и вторичный концепт» в аспектах стилевого и «ментального наполнения концепта» как «актуального слоя» в 
системе традиционных образов и понятий в национальной литературе [Bashkeeva, c.5].

Концепты, основанные на самобытные проявления народного мировидения, в лирике Семена Данилова создают одну из характерных черт якутской поэзии второй половины XX века, как «стремление к философскому осмыслению окружающей действительности через синтез лирического начала с публицистичностью или медитативностью» [Дьячковская, с.211]. Метафорическая система образов в его произведениях сложна и многогранна, он умеет вместить в малое пространство объемную поэтическую мысль, подкупающую с первых слов доверчивой открытостью к душе читателя. Непреходящую любовь народа к его творчеству известный литературовед И.Г.Спиридонов объяснил следующим образом: «Семен Данилов был мастером поэтического подтекста, передающего мироощущение личности, погруженной в размышление о том, что важно для всех. Он не просто поэтизировал глубину мыслей, но и обратил внимание читателей на эстетическую красоту раздумий человека о самом себе, о своем месте в природе и обществе, вел неустанные поиски и многое обрел на пути жизненного и философского насыщения образа» [Спиридонов, с.90].

Эти выводы исследователей подтверждают концептуальность как особый стилевой показатель поэзии Семена Данилова в целом. А именно то, что в стихахобращениях к читателю поэт дает лирическую характеристику своим произведениям в оригинальной по своей ощутимости системе образных умозаключений. В его творчестве, продолжающем традиции якутских классиков, лирическое раскрытие национально-исторических тем сочетается с простотой и естественностью выражения чувств и переживаний современного человека. Именно эта черта авторского стиля, стремление к лирическому раскрытию мыслей, обеспечивает плавные переходы от сложного к простому, от описания конкретного явления к выражению глубинной идеи при помощи оригинальных диалектически организованных концептов. Например, стихотворения «Олонхо кэнниттэн» («После олонхо»), «Дьиксинии» («Предчувствие»), «Уолбар» («Сыну»), поэмы «Хотой дьоло» («Счастье орла»), «Комсомол төлөннөөх сүрэбэ» («Анна») и др. Остановимся на первом из названных произведений, написанном в начале 1960-х годов:

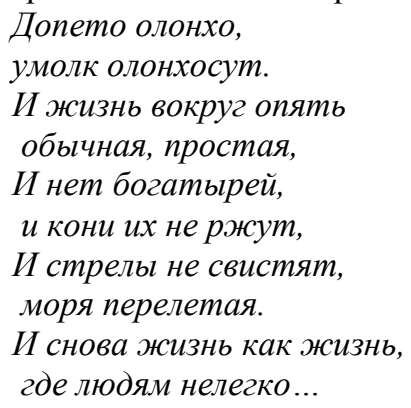

(Перевод М.Львова) [Данилов, с. 29]

В якутской поэзии олонхо часто равняется особому символическому образу, архетипу (первичному концепту). Но авторская метафора социально-философского ракурса в стихотворении Семена Данилова представляет индивидуальное переосмысление «большого времени», что поистине равняется метаобразу в сугубо национальном значении, не лишенном общечеловеческого современного восприятия реальности как лирический концепт вторичного типа. Динамика образного ряда 
«олонхо-время-жизнь» подчеркивается здесь сопоставлением «сложного и возвышенного» (олонхо) с таким же «сложным», но «реальным» (жизнь). Также концепт «допето олонхо» воспринимается как нечто очень важное, но однозначно законченное, безвозвратно ушедшее, что подтверждается с самого начала - в названии в лаконичном однозначном сочетании: «после олонхо».

Преклоняясь перед древними обычаями, историей и культурой родного народа, Семен Данилов написал в своем дневнике (запись относится к 1977 году): «Лелею мечту написать о якутских божествах - Айыы. Как хочется создать нечто цельное, возвышенное - о доброте и светлых устремлениях якутов ... Наши добрые божества и философия предков могут сгинуть без следа, не увидев солнца. Вот это будет бедствие...» [Данилов]. В русле этих размышлений поэта концепт олонхо, бесспорно, выступает ключевым понятием в обозначении времени давно минувшего, но несущего в себе знак духовной константы по отношению к его современнику.

Во втором томе Избранной лирики Семена Данилова находим другое стихотворение «Олонхо оқото» (приблизительно: «Ты потомок олонхо»), датированное началом семидесятых годов. Поэт обращается к современнику с напоминанием о его происхождении, где представленный нами концепт также наделяется функцией национальных духовных реалий психологического плана в форме скрытых сравнений смысла жизни со светлой идеей древнего сказания. Его художественные параметры - благородство и целеустремленность - создают периферийные направления концепта олонхо. Ключевая фраза поэта, основанная на уточнении названия произведения, повторяется дважды (в середине и конце стихотворения):

а) «Эн // Олонхо чобоо обото бун, // Олонхо омуна // Айбыт ыцччатыльын!»; б) «Эн олонхо о бото бун, // Омуннааах олонхо // ЫІтык ычччаты бын!!» [6: Т. 2, с. 325-326].

Дословный перевод текста представляем следующим образом:

а) $\mathrm{Tbl}_{\mathrm{l}} / /$ Смелое (любознательное) дитя олонхо, // Фантазия олонхо // Сотворила свое будущуее, тебя (свое растущеее поколение)!»; б) «Ть дитя олонхо // Фантастического олонхо // Светлое будущуее (растущуее поколение)».

Эти повторы отличаются всего двумя словами Эпитет «чобоо» - «смелый», «независимый в своих мыслях, словах» в первом случае подчеркивает, можно сказать, самодостаточность современника в своем времени. Значение эпитета «blтыл» во втором случае, скорее, относится к определению желания поэта в его обращении к современному молодому поколению быть ответственным перед мудростью олонхо.

В одном из ранних стихотворений автора «Олох уонна олонхо» («Жизнь и олонхо») впервые используется поэтический символ древнего эпоса в качестве узнаваемой якутским читателем устоявшейся метафоры. По сравнению с ним последующие обращения к этому образу отличаются качественным изменением значения и функции концепта олонхо в форме категории национальной культуры в индивидуальном стиле философской лирики Семена Данилова.

В исследованиях «концепта национальное» как одна из главных особенностей его значимости указывается «устойчивое проявление постоянных, излюбленных национальных мотивов, образов, глубоко специфического набора признаков, переходящих из произведения в произведение и позволяющих говорить о ментальной природе авторского мировидения» [Имихелова, с. 10]. В этом плане требуется подтверждение присутствия факультативных признаков концепта в представленном «литературном ряде» (в поэзии Семена Данилова). Это обращения в стихотворениях 
к образам олонхо, таким как Нюргун Боотур, Туйаарыма Куо, Далбар Хотун; к образам из якутских поверий и национальных обрядов, как Айыысыт, Хатан Тэмиэрийэ, ысыах, салама и др.

Значительное место в художественном наследии Семена Данилова занимает пейзажная лирика, в образах времен года заключается живой отголосок времени или судьбы человека, характера современника или его образа жизни. Например, зимний пейзаж представляется концептом снег, символизирующим чистоту стремлений человека, а также его обязанность оставлять потомкам благородный след от прожитых лет. Снежные просторы тундры и зимняя тайга в размышлениях поэта олицетворяют бесконечность времени, таящего противоречия жизни и судьбы, преодоления которых необходимы для самоутверждения человека. Назовем такие стихотворения, как «Хаар» («Снег»), «Маннайгы хаар» («Первый снег»), «Хаар сибэккилэрэ» («Цветы из снега»), «Кыһынны тыа» («Зимний лес»), «Кыһынны ырыа» («Зимняя песня»). Летний пейзаж, ассоциирующийся с тишиной белых ночей, тихой, умиротворенной картиной быта, раскрывает самоуглубленное спокойствие лирического героя, его восхищение трудолюбием родного народа, нежной девичьей красотой и целомудренностью якутских женщин. Концепты, представляющие истоки и общечеловеческие начала духовной культуры саха, можно представить названиями лирических произведений: «Намыын хоһоон» («Спокойное стихотворение», «Үрүн түүн» («Белая ночь»), «Сайынны Сиинэ» («Родная река Сиинэ летом»), «Сайынны хартына» («Картина лета»).

Весенний пейзаж у поэта, можно сказать, традиционен. Это радость пробуждению, обновлению природы, воспевание силы жизни, где концептами национального плана выступают подснежник, река Лена. Самобытны осенние картины в лирике Семена Данилова. Это время года выступает у него аналогом завершающего, итогового периода жизни. Осенние пейзажи часто пронизывают мотивы прощания, расставания с настоящим или особого - мудрого - понимания таинственных сил и законов природы. Это стихотворения «Күһүннү сарсыарда» («Осеннее утро»), «Күһүнү көрсө» («Встреча с осенью»), «Атырдьах ыйа» («Август») и др. Например, одно из них - «Күһүннү» («К осени»):

\section{Осенние сонни леса,}

Заполнены все зкрома золотыми дарами.

Тоскливы гусей голоса:

«И осень твоя, - мне кричат они, - не за горами...»

Скажу им с ульбкою я:

«Спасибо вам, гуси, за грустные ваши намеки.

Я знаю, придет и моя

Печальная осень, настанут последние сроки...»

Перевод М.Львова [Данилов, с. 218]

Поэтическая идея этих стихотворений развертывается от частного к универсальному, от обыденного, непритязательного, на первый взгляд, явления к преодолению «пространства» и «времени», что придает авторским обобщенным мыслям широту эпического содержания. Концепт осень в лирике Семена Данилова наделяется мотивами заката жизни в конкретных национальных параметрах восприятия природы: печаль в его картинах осени светлая, озаренная любовью, мудростью, благодарностью. Об этом подтверждает его запись в своем дневнике 3 октября 1972 года: «Осень. Оглянулся и увидел: оказывается, у меня много стихов об осени. Видимо, ее я предпочитаю другим временам года. Есть одна причина, которое 
делает мое предпочтение осени особенным: в это время я чувствую свое слияние с природой. Весной и осенью я неизменно стремлюсь к природе, чтобы с восторгом и упоением встретиться с ней - как охотник, как ее кровный сын, как поэт. Я хотел бы умереть осенью. Хотел бы спокойно проститься с родной природой и лечь в землю, подобно медведю, тихо засыпающему в берлоге... Весной, когда природа пробуждается, я пришел в этот солнечный мир. Уйти из жизни я должен в пору увядания его. Счастливые люди умирают осенью» [Данилов].

Семен Петрович Данилов ушел из жизни в конце в ноябре 1978 года.

Анализу взаимной связи природы и поэзии, что подтверждается в целом их естественной духовностью, посвящена одна из современных исследований: «Поэзия находит в природе не только свои ритмы и строфы, но прежде всего тот дух естественности, не предсказуемости, которым сама дышит. ... Природа - не только тема поэзии, но и наивысший ее идеал, та большая поэзия, которая уже не вмещается в индивидуальный стиль, выходит за границы авторства, стирает подписи, имена и становится плотью мира», - красиво и убедительно заключает М.Н.Эпштейн [Эпштейн, с. 16, 21].

В этом направлении аналитики пейзажные концепты якутского поэта выступают тем вторичным типом художественного воплощения вечной темы и вечных образов, где национальное мировидение отражается именно как исходное традиционное возвышение природы, отраженное в авторском представлении единства человека с природой родного края. Это и сам национальный образ пейзажа Якутии, и концептуальное раскрытие идеала в лирике именно Семена Данилова. Поэтические универсалии в данном случае выступают национальной константой, национальной единицей в индивидуальной системе образных координат.

Концепты национальной культуры в формах обращений к мотивам народных песен, благословений (алгысов), обрядовой поэзии особенно четко прослеживаются в стихотворениях, созданных во второй половине 1970-х годов. В этой связи можно представить сборник «Сэргэлээхэ көмүс ардах» («Золотой дождь в Сергеляхе»), составленный в основном из последних стихотворений поэта. Сборник впервые вышел в 1979 г, куда вошли первоначально 146 произведений [Данилов]. В заключительный третий том Избранной лирики Семена Данилова (1985 г.) он входит первой частью, состоящей из 149 стихотворений. Дополнительно включены три названия: «Быыкайкаан хоһооннор» («Короткие стихотворения»), «Максим Аммосов», «Натальи Харлампьевой» [Данилов: Т. 3, с. 5-201].

Главная особенность сборника в идейно-тематическом плане состоит в том, что здесь под одним названием собраны стихи-размышления о жизни человека. И главное отличие их - проходящий через весь сборник мотив конца, четкий образ времени в трех его измерениях. Характерно и то, что поэт после каждого стихотворения ставит дату написания, в некоторых - случаях место создания стихотворений. Напомним: Семен Данилов в других сборниках и прижизненных изданиях избранных редко отмечал время создания, произведения его лирика, обычно, группируется по годам с определением тематических направлений общим названием. Например, двухтомник 1977 г. начинается с части «Киһи барахсан» («Человек», 1966-1968) [4]. А первый том названного трехтомника составляют части: «Мин дойдум» («Мой родной край», 1937-1948); «Аймах дьонум» («Родные люди», 1949-1954); «Эйэлээх куорат» («Мирный город», 1955-1958); «Доэор хоһуун сүрэбэ» («Смелое сердце друга», 1959-1960); «Күн таммађа» («Капля солнца», 1961-1962); «Алаас сулустара» («Звезды аласа», 1963-1965) [Данилов: Т.1]. В целом в отсутствии 
четкости дат в книгах поэта не откажешь. Однако сборник «Золотой дождь в Сергеляхе» в этом плане все равно стоит особняком. В нем вошли стихи, написанные в основном в 1976-1978 г. и несколько произведений, датированных 1973, 1974 и 1975 годы. В Заключительном слове (от редактора) подчеркивается, что книга подготовлена автором, и первоначальное редактирование текстов проходило совместно с ним. Ныне народный поэт, редактор этого издания Михаил Тимофеев вспоминает друга, отмечает его доброжелательность, широкую эрудицию и выражает надежду, что поэзия Семена Данилова будет в последующем ценным предметом исследований литературоведов, при этом специально подчеркивает о необходимости текстологических работ по его лирикие [Данилов, с. 207-211].

Стихотворение «Мин кэриэһим» («Мое завещание»), открывающее сборник, можно сказать, готовит читателя к восприятию идеи всего сборника. А заключающее книгу произведение «Ытыллыбыт ох курдук» («Словно выпущенная стрела») раскрывает главный смысл завещания поэта, перекликающийся с образным народным высказыванием о краткости жизни человека, - лучше жить так, чтобы после говорили: «Прожил человек свой срок, словно меткая стрела». Все это подтверждает, что названный сборник Семена Данилова можно назвать Книгой стихотворений: во-первых, принимая во внимание, тематическое единство составляющих; во-вторых, особую значимость в сборнике авторского начала - в данном сборнике лирическое «я» выступает конкретным представлением автора, а именно, Семена Данилова.

Образы сборника национальны в духе особого «даниловского стиля»: это, во-первых, естественность поэтических высказываний. Обратимся к самому началу Книги стихов:

$$
\begin{gathered}
\text { «Сылаас, сырдык сыдьаайдан, } \\
\text { Саха оһобунуу! } \\
\text { Баай дууһалан, баай санаалан, } \\
\text { Саха тылыныы». } \\
\text { Хааммар сылдьар итинник } \\
\text { Өбүгэм кэриэһэ. } \\
\text { Өйбөр, сүрэхпэр диринник } \\
\text { Инпит үгэһэ. } \\
\text { «Сылаас, сырдык сыдьаайдан, } \\
\text { Саха оһобунуу! } \\
\text { Баай дууһалан, баай санаалан, } \\
\text { Саха тылыныы». } \\
\text { Көмүс, түүлээх баай оннугар, }
\end{gathered}
$$

Алгыһы кытары,

Кэриэс хаалларыам ыччаппар

Ити кэс тыллары.

1977 [Данилов, с. 3; 6: Т. 3, с. 6]

В повторяющихся первой и третьей строфах, представленных в форме прямой речи, заключаются основные концепты стихотворения. Их дословный перевод: «Будь носителем тепла и света // подобно якутской печи! // Будь щедрым душой и помыслами // как язык саха». Эти заветные слова поэт помнит как завет предков - вторая строфа; оставляет их своим благословением молодому поколению четвертая строфа. Здесь концепты якутская печь, якутский язык, алгыс (благословение) - главные образы стихотворения - представлены в двух смысловых 
вариантах: а) как то святое начало в душе Поэта, что его отличает от «других»; б) в виде его заветного желания, чтобы эти духовные истоки в их глубинных значениях остались после него. Восклицательный знак первого двустишия подтверждает особое волнение Поэта в обращении к потомкам, «спокойное» завершение строфы относим характерности стиля поэта, «тихой интонации» его лирики. Сравнение стихотворения с алгысом тоже несет две смысловые направления: а) святость обращения Поэта; б) можно сказать, возраст адресанта в том значении, что с алгысом обращаются старшие к молодым.

Эти образные параметры в их различных вариантах определяют своеобразие сборника «Золотой дождь в Сергеляхе», где начиная с заглавия, поэтически уточняются национальные и личностные начала Книги стихов. Например, эпитет «золотой» сопоставляется с пейзажем ранней осени в Якутии. «Дождь» ассоциируется с понятием природной благодати. «Сергелях» - реальное место размышлений Поэта, но с другой стороны, это слово связывается и с ментальным образом национальной интеллигенции как исконное название части территории Якутска, которая начинается с университетского городка и заканчивается на югозападном направлении местом дач и частных домов писателей.

В сборнике преобладают метафоры и сравнения природной этимологии. Однако образы времен года, пейзажные картинки в целом, подчиняясь логике размышлений о текучести времени, приобретают особую концептуальную значимость как приметы периодов жизни человека, его возраста, состояния души. Например, пейзажные мотивы лета связываются с воспоминаниями о детстве и юности («Песни детства», датированное; «Первое стихотворение», 1977). По сравнению с ними, в стихотворении «Мин дьылым хонуктара» (дословно: «Дни моих годов», 1975) названия месяцев как поэтические концепты раскрываются иначе:

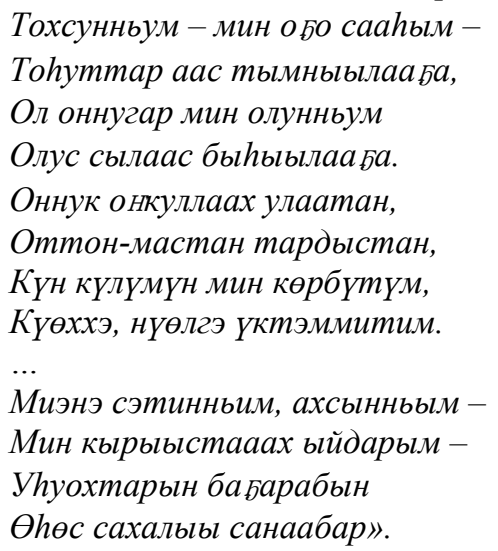

1975 [Данилов, с. 24-25; 6: Т. 3, с. 31-32]

Приведем свой примерный построчный перевод этих строф:

Январь - мое детство // Был слишком морозным, // Но февраль, как помню, // Был намного мягче.

В таком представлении я рос, // Держась, опираясь // Увидел свет солнща, // Наступил на зеленую траву.

Мои ноярбь, декабрь - // Проклятые месяџь // Я хочу, чтоб они задерживались (дольше не наступали), // Так думаю упрямо.

Здесь месяцы года выступают удачной метафорой для представления периодов жизни Поэта в контексте истории жизни общества: Январские трескучие 
морозы (Семен Данилов родился в 1917 г.) - время трудного детства, февральские потепления связываются с рождением светлых надежд. Далее в тексте вспоминается изменчивая мартовская погода, которую в пору юности Поэт не до конца понимал. Апрель и май остались в его жизни как самое яркое время, но зато в июне он получил урок жизни, что сравнивает с народным образным поучением о том, что «в июне беспечный малый может отморозить нос». В этой строфе Поэт напоминает о начале 1950-х годов, когда он, преподаватель Якутского педагогического института, обвиненный в национализме, остался без работы, без жилья, без надежды. Заканчивается стихотворение выражением желания, чтобы ноябрь и декабрь подольше не наступали, называя их «проклятыми» относительно своей судьбы месяцами.

В данном произведении концепт год выступает поэтическим символом жизни (срока жизни) человека. В небольшом по объему лирическом произведении раскрывается образ глубокого подтекста, где именно система представления эпизодов жизни равняется внутренней логической форме в четких границах семантически насыщенных динамических слов-символов, что поистине может восприниматься художественной реализацией одной из значительных функций концепта в параметрах математической лингвистики. Добавим к этому четкий ритм, утонченную рифму, парную аллитерацию строк, подчеркнутую начальными созвучиями. Вся эта красота формы и глубина подтекста достигается при практическом исключении развернутых эпитетов, сравнений и других типов тропа, обычно и естественно присутствующих в лирических формах. В стихотворении раздумья Поэта представляют постепенное развитие идеи Книги стихов в целом, где главной особенностью выступает обязательное присутствие мотивов начала и конца.

Следует дополнительно сказать о ритмико-интонационных характерностях произведений этого сборника Семена Данилова. Примерно $30 \%$ стихотворений написаны в форме свободного стиха, что определяется своеобразием психологической лирики. Самоуглубленное «подведение итогов» не всегда сочетается с четким обозначением ритмики. Более того, формы ряда произведений точнее можно определить как прозостих. Например, «Воспевание родины», «Итоги моего сорокалетнего труда...», «В доме Расула Гамзатова», «Жена поэта» и др. Некоторые из них разделены на строфы, но своеобразие их заключается именно не в уточнении ритма, а в завершении предложений, где реальность размышлений не допускает присутствия утонченной поэтической образности. Таким образом, сборник «Золотой дождь в Сергеляхе» значителен в двух основных качествах: во-первых, как показатель итоговых размышлений Поэта он посвящен молодому поколению и в нескольких аспектах перекликается с записями Семена Данилова в своем личном дневнике (названном Поэтом самым ценным в его творческом наследии). Во-вторых, в этой книге лирические переживания имеют особую ценность именно как реальные размышления о реальном времени с указанием даты, места и повода создания того или иного произведения.

Таким образом, в кратком представлении поэзии народного поэта Якутии в ракурсах освещения концептов национальной культуры приходим к следующим выводам. Реальность лирических переживаний, их многогранность и глубина подчеркиваются в спокойном и размеренном ритме психологической поэзии, что равняет национальное своеобразие образов общечеловеческому восприятию мира. И в этом заключается ментальное своеобразие его поэтического голоса, не утрачивающего и в переводах индивидуального авторского звучания. Можно 
напомнить образную характеристику народного поэта Башкортостана Мустая Карима в его воспоминаниях о Семене Данилове: «Краски его неброские, но прочные, долговечные, слова его не пронзительные, но слышны издалека. Вообще истину и веру кричать неудобно. Любовь - тем более... Громко говорят люди, живущие в маленьких переулках, на узких улицах, Якутию не прокричишь» [Карим, c. 160].

Концепты в лирической поэзии Семена Данилова равняются в целом единицам мышления и реализуются в процессе логически систематизированного образного раскрытия темы в аспектах памяти традиционной культуры. Например, концепты, основанные на фольклорных образах и народных представлениях. Наблюдаются и формы перетекания предмета лирического размышления в семантически открытый образ-представление, сопоставляемый с проблемами современной жизни общества, как например, времена года. В этих параметрах концепты в его художественном наследии в целом не относятся образам обычной картины мира носителей языка, а равняются к категориям основы культуры, ее ключевым понятиям и равняются объемным в смысловом понимании единицам информации и памяти в национальном мировосприятии.

\section{ЛИТЕРАТУРА}

1. Башкеева В.В. Введение. // Концепты в литературе Бурятии транзитивного периода. Коллективная монография. - Улан-Удэ: изд. БГУ, 2011. С. 3 - 9.

2. Володина Н.В. Концепты, универсалии, стереотипы в сфере литературоведения. - М.: Флинта, 2010. - 256 с.

3. Данилов С.П. Звучание тайги. М.: Советская Россия, 1972. - 336 с.

4. Данилов С.П. Избранное. В 2 тт. - Якутск: Книжное изд., 1977. Т. 1 - 440 с.

5. Данилов С.П. Сэргэлээххэ көмүс ардах (Золотой дождь в Сергеляхе). Якутск: Книжное изд., 1979. - 216 с.

6. Данилов С.П. Избранное. В 3 тт. - Якутск: Книжное изд., 1984, 1985. - Т. 1 432 с.; Т $2-432$ с.; Т $3-368$ с.

7. Данилов С.П. Мысль окрыляющая. Страницы из дневника. // Литературная Россия. - 1989. - 5 мая.

8. Дьячковская М.Н. Основные тенденции развития якутской поэзии ХХ века. Шестидесятые - семидесятые годы // Литература Якутии XX века. Коллективная монография. - Якутск: Изд. ИГИ АН РС(Я), 2005. - 728 с.

9. Имихелова С.С. Концепты национальное в бурятской русскоязычной литературе // Концепты в литературе Бурятии транзитивного периода. Коллективная монография. - Улан-Удэ: изд. БГУ, 2011. С. 9 - 18.

10. Карим М. Притча о трех братьях. - М.: Современник, 1988. - 367 с.

11. Спиридонов И.Г. «Бу тыллар буолбатах - кубалар...». Статьи. Якутск: Изд. «Бичик», 2002. - 230 с.

12. Эпштейн М.Н. Стихи и стихия. Природа в русской поэзии XVIII - XX вв. Самара: ИД «Бахрах-М», 2007. - 352 с.

\section{LITERATURE:}

1. Bashkeeva V.V. Vvedenie. // Kontsepty v literature Buryatii tranzitivnogo perioda. Kollektivnaya monografiya. - Ulan-Udeh: izd. BGU, 2011. S. 3 - 9.

2. Volodina N.V. Kontsepty, universalii, stereotipy v sfere literaturovedeniya. - M.: Flinta,2010. - $256 \mathrm{~s}$.

3. Danilov S.P. Zvuchanie tajgi. M.: Sovetskaya Rossiya, 1972. - 336 s.

4. Danilov S.P. Izbrannoe. V 2 tt. - Yakutsk: Knizhnoe izd., 1977. T. 1 - 440 s. 
5. Danilov S.P. Sehrgeleekhe kөmys ardakh (Zolotoj dozhd' v Sergelyakhe). Yakutsk: Knizhnoe izd., 1979. - 216 s.

6. Danilov S.P. Izbrannoe. V 3 tt. - Yakutsk: Knizhnoe izd., 1984, 1985. - T. 1 - 432 s.; T $2-432$ s.; T $3-368$ s.

7. Danilov S.P. Mysl' okrylyayushaya. Stranitsy iz dnevnika. // Literaturnaya Rossiya. $-1989 .-5$ maya.

8. D'yachkovskaya M.N. Osnovnye tendentsii razvitiya yakutskoj poehzii XX veka. Shestidesyatye - semidesyatye gody // Literatura Yakutii XX veka. Kollektivnaya monografiya. - Yakutsk: Izd. IGI AN RS(YA), 2005. - 728 s.

9. Imikhelova S.S. Kontsepty natsional'noe v buryatskoj russkoyazychnoj literature // Kontsepty v literature Buryatii tranzitivnogo perioda. Kollektivnaya monografiya. - UlanUdeh: izd. BGU, 2011. S. 9 - 18.

10. Karim M. Pritcha o trekh brat'yakh. - M.: Sovremennik, 1988. $-367 \mathrm{~s}$.

11. Spiridonov I.G. «Bu tyllar buolbatakh - kubalar...». Stat'i. Yakutsk: Izd. «Bichik», 2002. $-230 \mathrm{~s}$.

12. Epshtejn M.N. Stikhi i stikhiya. Priroda v russkoj poehzii XVIII - XX vv. Samara: ID «Bakhrakh-M», 2007. - 352 s.

Об авторе: Сивцева-Максимова Прасковья Васильевна, доктор филологических наук, профессор кафедры якутской литературы Северо-Восточного федерального университета имени М.К.Аммосова, зав.научно-исследовательской лабораторией «Проблемы текстологии и литературной критики» при Институте А.Е.Кулаковского СВФУ.

Тел.: 8-914-222-24-90

About the author: Praskovya V. Sivtseva-Maksimova

Doctor of Philology, professor of the Department of the Yakut literature of NorthEastern Federal University named after M. K. Ammosov, head.research laboratory "Problems of textual criticism and literary criticism" at the Institute of A. Y. Kulakovsky NEFU.

Tel.: 8-914-222-24-90 